die von der Entschälung der Seide herkommenden eiweissartigen Körper und einen grossen Theil des gelben Farbestoffs. Man trennt das Fett von den übrigen Gemengtheilen durch Pressen des Niederschlages, Anrühren desselben mit verdünnter roher Salzsäure und Abgiessen der Salzlösung. Die Fettsäuren und die eiweissartigen Körper scheiden sich als klebrige, mehr oder minder zusammenhängende Masse $a b$, aus der beim Stehenlassen in Schalen auf dem Wasserbade bald eine grosse Menge Fett ausfliesst. Dieses kann leicht klar abgegossen werden. Der Rest, der in dem Kuchen zurückbleibt, lässt sich durch warmes Pressen ziemlich vollständig gewinnen. Das Fett ist gelblich, bei gewöhnlicher Temperatur fest, hat einen Schmelzpunct von 35 bis $39^{\circ} \mathrm{C}$.

Es erhielten Herr Isler, Polytechniker in Zürich, auf dem angegebenen Wege 1,48 Proc., Herr Pierz aus einer Brühe 2,3 Proc., aus einer andern 0,60 Proc. Fettsäuren. Es ist sehr natürlich, dass der Fettsäurengehalt der verschiedenen Flüssigkeiten verschieden ausfalle, da nicht zu jeder Operation des Abkochens gleich starke Seifenlaugen dienen. (Schweiz. Zeitschr. fiir Polytechnik. 1859. Bd.4. S. 55.) Bkb.

\title{
Ueber Anwendung des Paraffins zu chemischen Zwecken.
}

Der billige Preis des Paraffins (München pr. Zollpfd. $54 \mathrm{kr}$.) veranlasst Dr. Vogel $\mathrm{zu} \mathrm{dem}^{\circ}$ Glauben, dass dasselbe häutig in chemischen Laboratorien Anwendung finden wird, da bekanntlich weder Chlor, noch ätzende Alkalien, noch Säuren darauf einwirken, ja dasselbe sogar die Destillation mit concentrirter Schwefelsäure erträgt, ohne dadurch zersetzt zu werden.

Dr. Vogel empfiehlt nun zuerst Paraffinbäder statt der bisher gebräuchlichen Oelbäder. Da tasselbe schon bei $45^{\circ} \mathrm{C}$. schmilzt, so können die mit den zu trocknenden Substanzen gefüllten Glasgefässe ohne Gefahr des Zerspringens eingesetzt werden. Die Reinigung der Gefässe geschieht wie bei den Oelbädern durch Benzol und Vogel benutzt schon seit Monaten ein Paraffinbad von 300 Grm. Gehalt, ohne eine Schwärzung oder Aenderung bemerkt zu haben, obgleich die Temperatur desselben häufig über $250^{\circ} \mathrm{C}$. gestiegen und andauernd erhalten ist.

Sodann empfiehlt derselbo mit Paraftin getränktes Papier zur Deckung und zu Etiketten auf Standgefässen für 
Säuren und Alkalien. $\mathrm{Zu}$ diesem $\mathrm{Zwecke}$ soll man die Aufschriften erst wie bei Anwendung von Firniss mit einer dünnen Lösung von arabischem Gummi überziehen und nach dem Trocknen bis auf $1000 \mathrm{C}$. etwa erhitztes Paraffin auftragen.

Selbst wässerige Flusssäure lässt sich in Glasgefässen verwahren, welche nur mit einer dünnen Lage Paraffin versehen sind.

Schwämme und Papier mit Paraffin getränkt, sind den mit Wachs dargestellten Präparaten weit vorzuziehen; auch scheint sich dasselbe zum Conserviren der Früchte sehr gut zu eignen, da Aepfel und Birnen, in schmelzendes Paraffin getaucht, sich mehrere Monate unter ungünstigen Umständen aufbewahrt, in unveränderter Frische erhalten haben. Wie weit sich dasselbe zum Conserviren von Eiern und saftreichen Früchten qualificirt, werden weitere Beobachtungen zeigen.

Schliesslich erwähnt Vogel noch der Methode des Prof. v. Kobcll, Auflösungen leicht sich oxydirender Substanzen unter einer schützenden Decke von schmelzendem Paraffin rorzunehmen. Die bisher in einer Atmosphäre von Kohlensäure oder mittelst des Mohr'schen Ventilrohres vorgenommenen Sicherungen gegen den Einfluss des Sauerstoffs können nun in offenen Porcellanschalen ausgeführt werden, indem man eine deckende Parafinschicht hervorbringt. Die Lösung soll unter der Paraffindecke vollkommen gegen Luft abgeschlossen, ja auch das fest gewordene Paraffin hält die Luft so ab, dass eine durch Zink reducirte Eisenoxydsalzlösung nach nehrtägigem Stehen keine Veränderung zeigte. $\mathrm{Da}$ das $\mathrm{Pa}$ raffin vom Chamäleon nicht afficirt wird, so kann man dasselbe ohne Nachtheil mit der Lösung in ein Becherglas zur Titrirung spülen. (Dingl.Journ. Bd.163. H. 2.) $B k b$.

\section{Ueber die Analyse des käufichen Kupfers.}

Bei der gewöhnlichen Analyse des Kupfers, Lösung in Salpetersalzsäure, Fällung durch Schwefelwasserstoff und Digestion mit einern Ueberschuss von Schwefelwasserstoff-Ammoniak kann nicht nur 1 Proc. Arsen, sondern es können auch 20 bis 30 Proc. Zinn der Bestimmung entgehen, weil das Schwefelkupfer die Auflösung der Sulfuride des Arseniks und Zinns in SchwefelwasserstoffAmmoniak verhindert. F. A. Abel und F. Field empfehlen nun: Lösung in Salpctersäure und nach dem 